\title{
Article \\ Effect of Assembly Unit of Expansive Agents on the Mechanical Performance and Durability of Cement-Based Materials
}

\author{
Lin Wang ${ }^{1}$, Chunxue Shu ${ }^{1}$, Tiantian Jiao ${ }^{1}$, Yong Han ${ }^{1}$ and Hui Wang ${ }^{2,3, *}$ \\ 1 School of Civil and Transportation Engineering, Beijing University of Civil Engineering and Architecture, \\ Beijing 100044, China; wanglin1@bucea.edu.cn (L.W.); shuchunxue@bucea.edu.cn (C.S.); \\ jiaotiantian@bucea.edu.cn (T.J.); yonghan@bucea.edu.cn (Y.H.) \\ 2 School of Civil and Environmental Engineering, Ningbo University, Ningbo 315000, China \\ 3 State Key Laboratory of Materials-Oriented Chemical Engineering, Nanjing University of Technology, \\ Nanjing 210000, China \\ * Correspondence: wanghui4@nbu.edu.cn
}

Citation: Wang, L.; Shu, C.; Jiao, T.; Han, Y.; Wang, H. Effect of Assembly Unit of Expansive Agents on the Mechanical Performance and Durability of Cement-Based Materials. Coatings 2021, 11, 731. https://doi.org/10.3390/ coatings11060731

Academic Editor: Luigi Calabrese

Received: 30 May 2021

Accepted: 15 June 2021

Published: 18 June 2021

Publisher's Note: MDPI stays neutral with regard to jurisdictional claims in published maps and institutional affiliations.

Copyright: (c) 2021 by the authors. Licensee MDPI, Basel, Switzerland. This article is an open access article distributed under the terms and conditions of the Creative Commons Attribution (CC BY) license (https:// creativecommons.org/licenses/by/ $4.0 /)$.

\begin{abstract}
This paper studies the influence of assembly unit of expansive agents $(\mathrm{CaO}$ and calcium sulphoaluminate) on the limited and free compressive strengths, the limited expansion rate, carbonation resistance, chloride ion penetration resistance and corrosion resistance of reinforcement concrete. The dosages of expansive agent were $0 \%, 3 \%, 6 \%, 9 \%$, and $12 \%$ by the total amount of cementitious materials. Two kinds of mineral admixture (blast furnace slag and fly ash) were applied in this study. Results show that suitable dosage (lower than or equal to $9 \%$ ) of double expansion agent with a large amount of mineral admixtures can improve the limited and free compressive strengths. However, when the dosage of the double expansion agent is higher than $9 \%$, the addition of the double expansion agent leads to the reduction of limited and free compressive strengths. The variation of the limit expansion rate reaches the maximum value when the curing age is 14 days. The increasing addition of expansive agents and lower water-binder ratio demonstrate positive effect on the limited expansion rate. Concrete with 60\% mineral admixtures (fly ash and ground granulated blast furnace slag) shows lower limited expansion rate and higher compressive strength than the concrete with 50\% mineral admixtures. Finally, the incorporation of double expansion agent can improve the resistance to carbonation, chloride ion penetration resistance, anti-corrosion of steel bars and mechanical strengths (the limited and free compressive strengths).
\end{abstract}

Keywords: expansive agents; compressive strength; expansion rate; carbonation resistance; chloride ion penetration

\section{Introduction}

At present, China is still in the period of large-scale infrastructure construction. The amount of concrete used is huge, and the problem of concrete durability still troubles many engineers and scholars [1-5].

Buildings in coastal cities are constantly updated. In these cities, concrete constructions are usually exposed to various corrosive environments. The complex service environment includes $\mathrm{NaCl}$ freeze-thaw, penetration corrosion of chloride, carbonation and their coupling effects, etc. In concrete constructions, steel bars are usually applied. The carbonation and chloride action could accelerate the corrosion of steel bars. Some researches reported that the addition of rust inhibitor could improve the corrosion resistance of steel bars [6-9]. On the other hand, increasing the compactness of concrete could help improve the impermeability of chloride ions in concrete thus improving the corrosion resistance of steel bars in concrete. Additionally, the incorporation of cementitious materials (blast furnace slag powder, fly ash and rice husk ash) could help improve the structure of cement paste thus enhancing the corrosion resistance of steel bars. 
Cracks and pores occur when the concrete structures are in the early stages, which will reduce the durability of cement concrete. Moreover, cracks in cement concrete induced by the effect of external forces, huge hydration heat or other corrosion effect usually decrease the mechanical strength and durability of cement concrete. In practical engineering, the cracking is often restrained by adding expansion agent to compensate the shrinkage, when concrete is in the early curing stage $[1,7,10,11]$. Calcium oxide and calcium sulphoaluminate are two kinds of expansive agent which has been used for the prevention of concrete cracks. When the two kinds of expansive agent are used in cement, the main hydration products are $\mathrm{Ca}(\mathrm{OH})_{2}$ and ettringite forms when reacted with water. The lime expansive agent is made of Cao calcined at a certain temperature. The hydration product $\left(\mathrm{Ca}(\mathrm{OH})_{2}\right)$ has the advantage of large expansion. However, $\mathrm{Ca}(\mathrm{OH})_{2}$ is easily soluble in water and reacts with carbon dioxide in the air thus reducing the durability of concrete [12]. At the same time, the hydration reaction of this kind of expansive agent is easily affected by temperature and humidity, so it is not suitable for major volume concrete. Calcium sulphoaluminate expansive agent has a large amount of early expansion, and the expansion is mainly concentrated in 3-14 days [13]. It can establish a certain pre compression stress in the early stage of concrete (construction period) to offset the early shrinkage of concrete. The shrinkage drop of expansive agent in the later stage is large, and it has no obvious compensation effect on the temperature shrinkage and drying shrinkage of hydraulic mass concrete in the middle and later stage. However, these kinds of expansive agent have been applied in engineering for many years. The assembly unit of these kinds of expansive agents may be favorable for durability, especially the corrosion resistance of reinforced concrete $[14,15]$. However, little attention has been paid to the influence of assembly unit of these kinds of expansive agents on mechanical strength, limited expansion rate, and resistance to carbonation.

This paper aimed to study the influence of assembly unit of expansive agents $(\mathrm{CaO}$ and calcium sulphoaluminate) on the limited expansion rate, compressive strength, carbonation resistance and chloride ion penetration resistance. Moreover, the corrosion resistance of reinforcement concrete was studied. Water-binder ratios in this study were 0.44 and 0.33 . We mixed $60 \%$ and $50 \%$ mineral admixtures (assembly unit of fly ash (FA) and ground granulated blast furnace slag (GGBS) in the concrete, respectively.

\section{Experimental}

\subsection{Raw Materials}

An assembly unit of expansive agents ( $\mathrm{CaO}$ and calcium sulphoaluminate) was used in this study. Table 1 shows the oxide compositions of the assembly unit of expansive agents. P.O 42.5 cement Type II fly ash (FA) and S95 GGBS produced by Yushuzhuang Component Factory (Beijing, China) were used as cementitious materials. The aggregates used in this study were river sand (fine aggregate) with fineness modulus of 2.35 and crushed gravels (coarse aggregates) with a maximum size of $20 \mathrm{~mm}$ and a crushed index of $4.8 \%$. Moreover, polycarboxylate superplasticizer water-reducing agent with a water reduction rate of about $25 \%$ was used to adjust the fluidity. The specific surface areas of FA, GGBS and cement in this study were 387,421 , and $391 \mathrm{~m}^{2} / \mathrm{kg}$, respectively.

Table 1. Mass percentage content of each component of expansive agents (\%).

\begin{tabular}{ccccccc}
\hline $\mathrm{SiO}_{2}$ & $\mathrm{Al}_{2} \mathrm{O}_{3}$ & $\mathrm{Fe}_{2} \mathrm{O}_{3}$ & $\mathrm{CaO}$ & $\mathrm{MgO}$ & $\mathrm{SO}_{3}$ & $\mathrm{TiO}_{2}$ \\
\hline 3.61 & 3.79 & 1.43 & 82.79 & 0.13 & 7.58 & 0.27 \\
\hline
\end{tabular}

\subsection{Samples Preparation and Measurement}

In order to manufacture the cement concrete, the process is shown as follows:

Firstly, cement, sand and coarse aggregate were added to the concrete mixer (Shike Co., Ltd, Zhengzhou, China) and stirred at a low speed of $60 \mathrm{rpm}$ for $1 \mathrm{~min}$, and then water was added and stirred for another $2 \mathrm{~min}$. Finally, all fresh mixture was poured into oiled 
molds (Kaiyue Co., Ltd, Cangzhou, China) to form testing specimens with sizes of $100 \mathrm{~mm}$ $\times 100 \mathrm{~mm} \times 100 \mathrm{~mm}, 100 \mathrm{~mm} \times 100 \mathrm{~mm} \times 300 \mathrm{~mm}, 100 \mathrm{~mm} \times 100 \mathrm{~mm} \times 400 \mathrm{~mm}$ and $\Phi 100 \mathrm{~mm} \times 400 \mathrm{~mm}$. Specimens with the size of $100 \mathrm{~mm} \times 100 \mathrm{~mm} \times 100 \mathrm{~mm}$ were used for the measurement of carbonation depth and compressive strength. Meanwhile, specimens with size of $100 \mathrm{~mm} \times 100 \mathrm{~mm} \times 300 \mathrm{~mm}, 100 \mathrm{~mm} \times 100 \mathrm{~mm} \times 400 \mathrm{~mm}$ and $\Phi 100 \mathrm{~mm} \times 400 \mathrm{~mm}$ were used for the measurement of mass loss of steel bars in the concrete (as shown in Figure 1), the measurement of the expansion (as shown in Figure 2) and the chloride ion penetration of concrete. All specimens were cured in a standard curing environment $\left(18-22{ }^{\circ} \mathrm{C}\right.$ and above $95 \%$ relative humidity). The mixing proportions of all specimens are shown in Table 2. In this study, the mass ratios of the mineral admixtures (FA and GGBS) to the total binder materials for groups A and B were $50 \%$ and $60 \%$, respectively. The mass ratio of FA to GGBS was 1.5:1. After standard curing, experimental space with constant temperature $20 \pm 2{ }^{\circ} \mathrm{C}$ and relative humidity of $55 \%-65 \%$ was provided for the measurement of the limited expansion rate, compressive strength, carbonation resistance, and chloride ion penetration resistance. The compressive strength was conducted according to the Chinese standard GB/T 50204-2002.

$\mathrm{mm}$
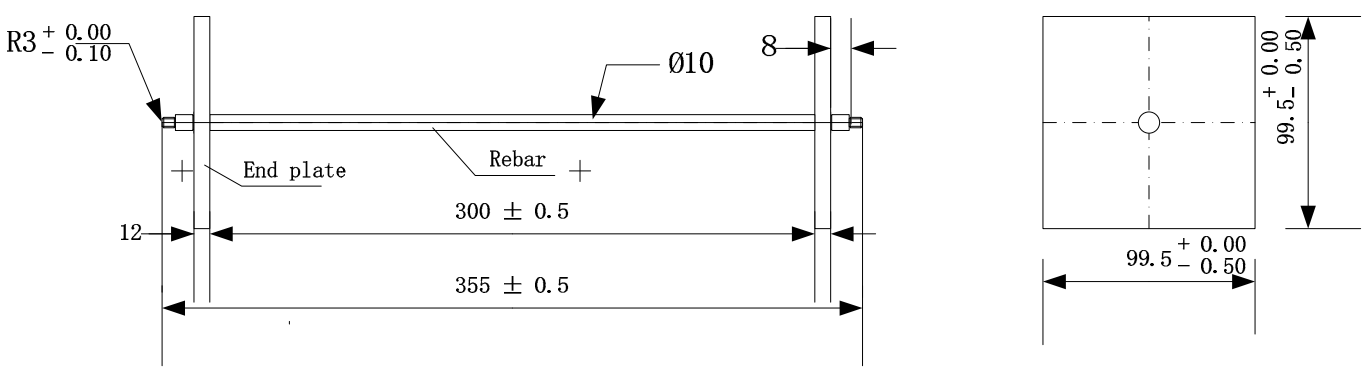

Figure 1. The measurement of mass loss of steel bars.

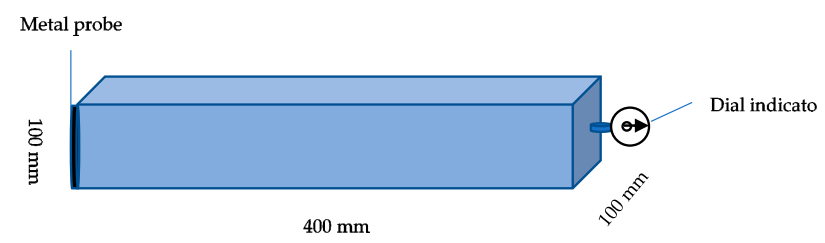

(a)

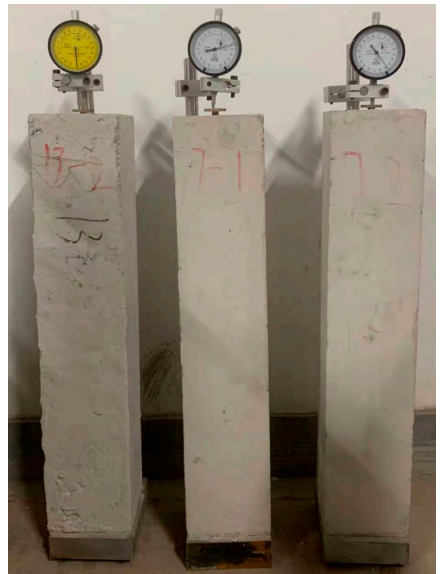

(b)

Figure 2. Measurement of the expansion rate of specimen, (a) schematic diagram, (b) real diagram.

The shrinkage rod of the dial indicator (Kaiyue Co., Ltd, Cangzhou, China) supports the middle of one end of the rectangular specimen. When the length of the specimen changes, the dial indicator reads out the value of the length change. Through this method, the expansion value was measured. When the carbonation experiment was carried out, each specimen was cured for 28 days and then placed in type CCB-70F automatic concrete carbonation test box produced by Tianjin Deste Instrument Technology Co., Ltd (Tianjing, China), with $20 \% \mathrm{CO}_{2}$ by mass ratio of the total mass of gas for 30 days and 60 days, respectively. After curing, all specimens were dried in a vacuum drying oven (Shanghai Yi Heng Instrument Co., LTD DZF-6020, Shanghai, China) at $60{ }^{\circ} \mathrm{C}$ for $48 \mathrm{~h}$. When dried 
in the oven, the sides were sealed with paraffin; however, two bottom surfaces were not. After carbonation, the carbonation depth was measured according to Chinese Standard GB/T 50082-2009. When a chlorine ion penetration test was carried out, all specimens were treated in the BSJ concrete intelligent vacuum water filling machine produced by Shanghai Meiyu Instrument Equipment Co., Ltd (Shanghai, China). After water saturation, an ion penetration experiment was conducted. The tests of carbonation depth and chloride ion penetration were performed according to Chinese standard GB/T 50082-2009. The weight loss rate of steel bars after carbonation was measured by the steps as follows:

Firstly, the steel bars were polished and the mass of the steel bars was weighed before carbonation. After carbonation the specimens were crushed and polished. Finally, the mass of the steel bars after carbonation was weighed and the weight loss rate of steel bars in concrete was calculated.

Table 2. The mix ratio of concrete with water-binder ratios of 0.33 and $0.43\left(\mathrm{~kg} / \mathrm{m}^{3}\right)$.

\begin{tabular}{ccccccccc}
\hline Samples & Cement & FA & GGBS & Expansive Agents & Water & Sand & Stone & Water-Reducing Agent \\
\hline W/B-0.43-A-0\% & 185 & 111 & 74.0 & 0 & 159.1 & 837 & 1023 & 3.7 \\
W/B-0.43-A-3\% & 179.5 & 107.7 & 71.8 & 11.1 & 159.1 & 837 & 1023 & 3.7 \\
W/B-0.43-A-6\% & 173.9 & 104.3 & 69.6 & 22.2 & 159.1 & 837 & 1023 & 3.7 \\
W/B-0.43-A-9\% & 168.3 & 101 & 67.3 & 33.3 & 159.1 & 837 & 1023 & 3.7 \\
W/B-0.43-A-12\% & 162.8 & 97.7 & 65.1 & 44.4 & 159.1 & 837 & 1023 & 3.7 \\
W/B-0.43-B-0\% & 148 & 148 & 98.7 & 0 & 159.1 & 823 & 1006 & 3.7 \\
W/B-0.43-B-3\% & 143.6 & 143.6 & 95.7 & 11.1 & 159.1 & 823 & 1006 & 3.7 \\
W/B-0.43-B-6\% & 139.1 & 139.1 & 92.7 & 22.2 & 159.1 & 823 & 1006 & 3.7 \\
W/B-0.43-B-9\% & 134.7 & 134.7 & 89.8 & 33.3 & 159.1 & 823 & 1006 & 3.7 \\
W/B-0.43-B-12\% & 130.1 & 130.1 & 86.7 & 44.4 & 159.1 & 823 & 1006 & 3.7 \\
W/B-0.33-A-0\% & 243.3 & 146.0 & 97.3 & 0 & 162 & 698 & 1047 & 4.4 \\
W/B-0.33-A-3\% & 237.7 & 142.6 & 95.1 & 14.7 & 162 & 698 & 1047 & 4.4 \\
W/B-0.33-A-6\% & 230.3 & 138.2 & 92.1 & 29.4 & 162 & 698 & 1047 & 4.4 \\
W/B-0.33-A-9\% & 223.0 & 133.8 & 89.2 & 44.1 & 162 & 698 & 1047 & 4 \\
W/B-0.33-A-12\% & 215.7 & 129.4 & 86.3 & 58.8 & 162 & 698 & 1047 & 4.4 \\
W/B-0.33-B-0\% & 196.0 & 196 & 130.7 & 0 & 162 & 715 & 1073 & 4.4 \\
W/B-0.33-B-3\% & 190.1 & 190.1 & 126.7 & 14.7 & 162 & 715 & 1073 & 4.4 \\
W/B-0.33-B-6\% & 184.2 & 184.2 & 122.8 & 29.4 & 162 & 715 & 1073 & 4.4 \\
W/B-0.33-B-9\% & 178.4 & 178.4 & 118.9 & 44.1 & 162 & 715 & 1073 & 4.4 \\
W/B-0.33-B-12\% & 172.5 & 172.5 & 115.0 & 58.8 & 162 & 715 & 1073 & 4.4 \\
\hline
\end{tabular}

\section{Results and Discussion}

\subsection{Compressive Strength}

Figures 3 and 4 show the compressive strength of specimens cured with and without formwork for different times. The water to binder ratios of Figures 3 and 4 are 0.33 and 0.43, respectively. In this study, the limited compressive strength means the compressive strength of specimens cured with formwork. Meanwhile, free compressive strength means the compressive strength of specimens cured without formwork. As illustrated in Figures 3 and 4, the compressive strength of specimens increases with increasing curing age. Moreover, the addition of expansive agents is able to increase the limit and free strengths when the dosage of expansive agents is less than $9 \%$. However, when the content of expansive agents is higher than $9 \%$, the limit and free strengths decrease with the increasing dosage of expansive agent. This is attributed to the fact that an appropriate amount of expansive agent (lower than 9\%) can improve the compactness of cement-based materials [16,17]. Additionally, the increasing dosage of mineral admixtures can decrease the compressive strength of concrete at an early age (less than 28 days) and at the curing age of 56 days the addition of mineral admixtures results in the improvement of the compressive strength due to the reaction of calcium hydroxide with fly ash and slag powder, which makes the concrete more dense $[18,19]$. Comparing Figures 3 and 4 , it can be found that the increased strength grade results in the improvement of limited and free compressive strengths. 


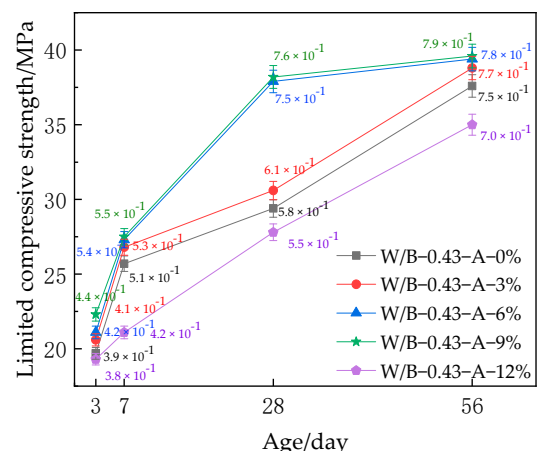

(a)

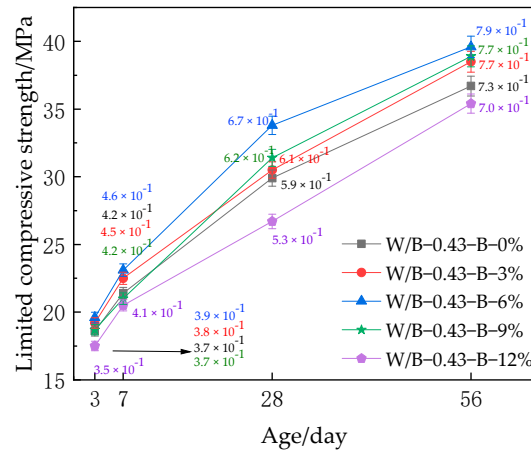

(c)

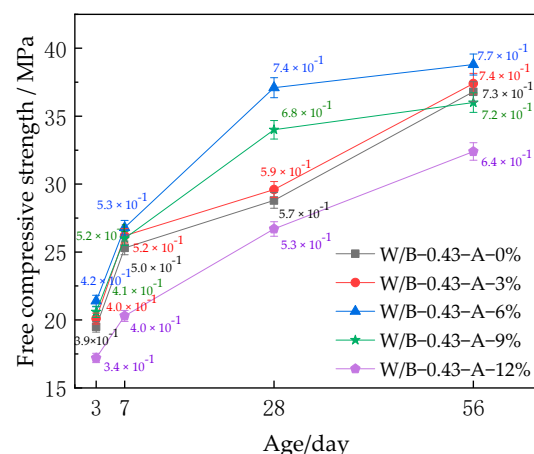

(b)

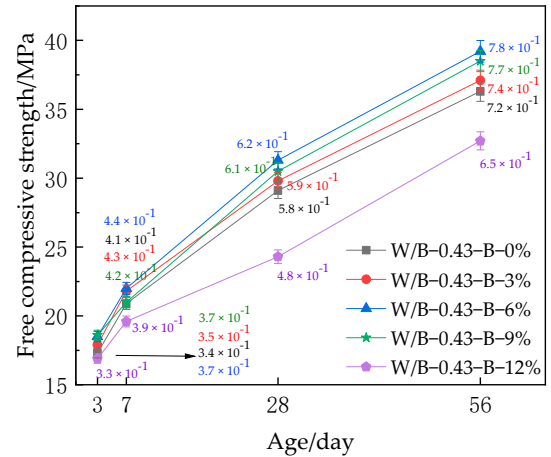

(d)

Figure 3. Compressive strength of concrete with water-binder ratio of 0.43 . (a) Limited strength of group A, (b) free strength of group A, (c) limited strength of group B, (d) free strength of group B.

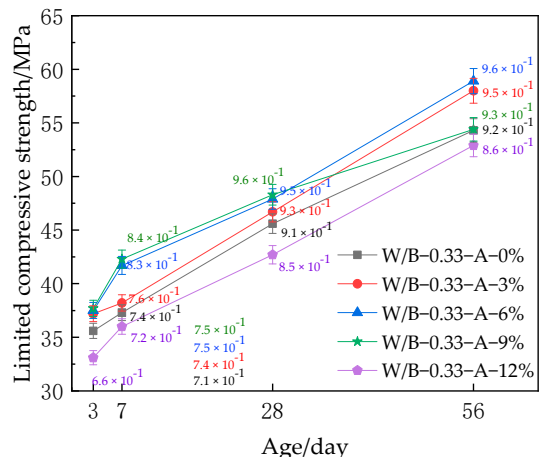

(a)

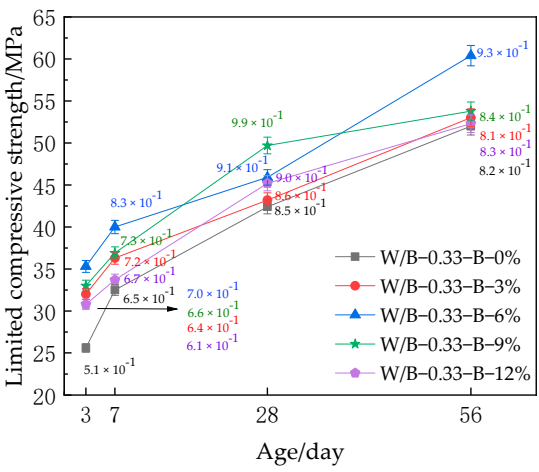

(c)

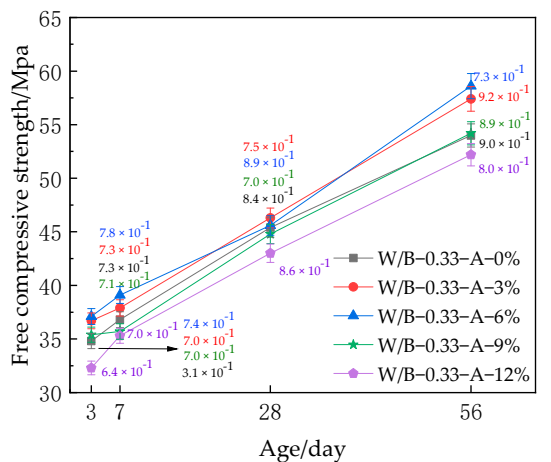

(b)

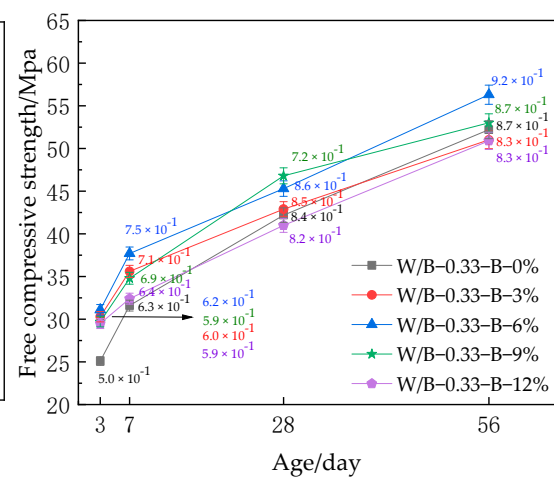

(d)

Figure 4. Compressive strength of concrete with water-binder ratio of 0.33 . (a) Limited strength of group A, (b) free strength of group A, (c) limited strength of group B, (d) free strength of group B. 


\subsection{The Expansion Rate}

Figure 5 shows the limited expansion rate of concrete (concrete is cured with formwork) varying with curing age and the content of expansive agents. It can be observed from Figure 5 that the limited expansion of specimens with the addition of expansive agents rate firstly increases and then decreases with increasing curing age. When the curing age is 14 days, the limited expansion rate is the highest. Moreover, the addition of the total mineral admixtures (fly ash and blast furnace slag) can effectively decrease the limited expansion rate of concrete due to the fact that fly ash possesses a good pozzolanic effect and can react with sulfate and $\mathrm{Ca}(\mathrm{OH})_{2}$ leading to the reduction of $\mathrm{pH}$ value in the liquid phase of concrete. Therefore, with the increasing addition of fly ash content, the effect is more obvious [20]. With the volcano ash reaction of fly ash, the calcium silicate gel with stable gel properties is formed, filling pores, improving the pore structure and pore distribution of concrete, leading to a decreasing expansion rate of concrete. As shown in Figure 5, the limited expansion rate of the specimens without limited expansion is positive when the curing age is 14 days, however, when the curing age is higher than $14 \mathrm{~d}$, the limited expansion rate is negative. Figure 5 also shows that the water-binder ratio can decrease the limited expansion rate of concrete. This is attributed to the fact that for the concrete with lower water-binder ratio, the increase of double expansion source expansion agent will lead to the early end of expansion due to the lack of water in the later period of empty curing, which will lead to a significant reduction of the limited expansion rate [21].

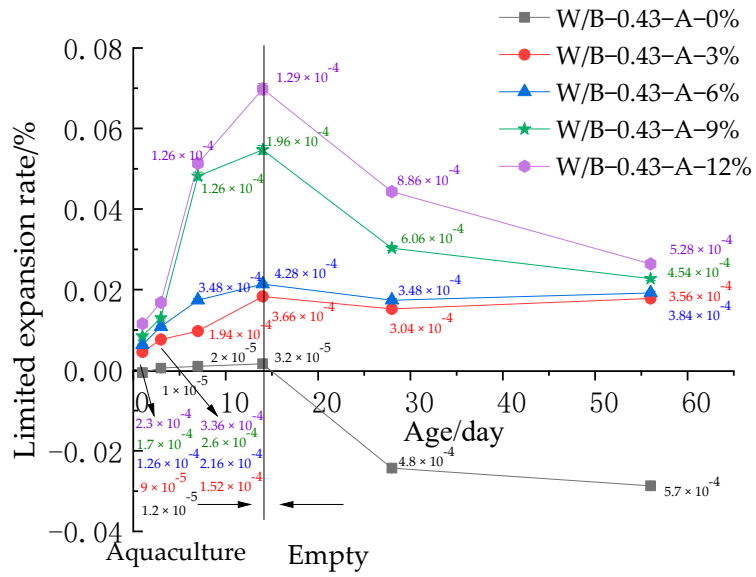

(a)

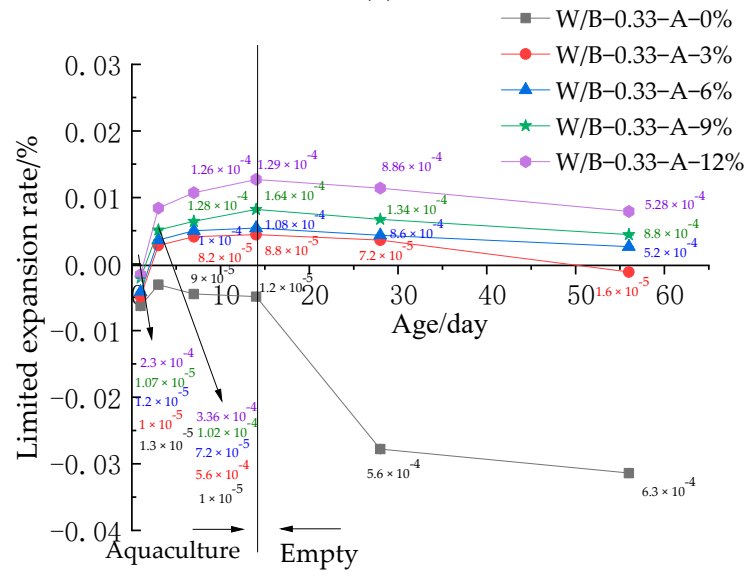

(c)

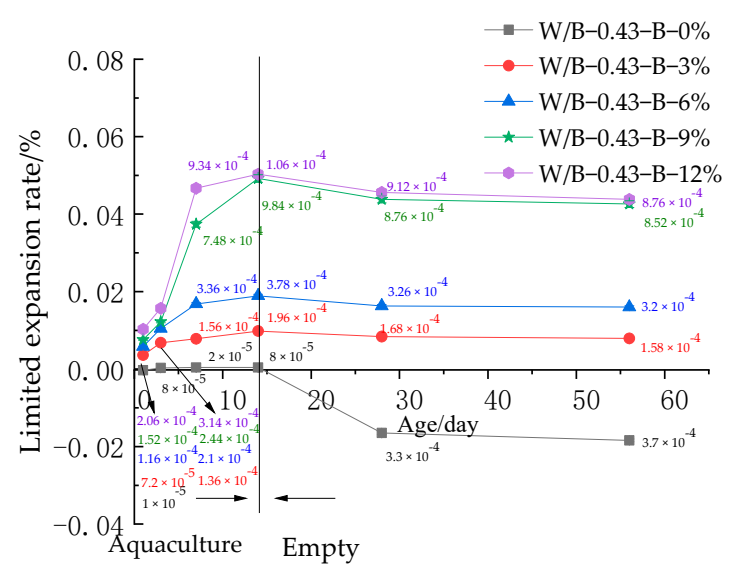

(b)

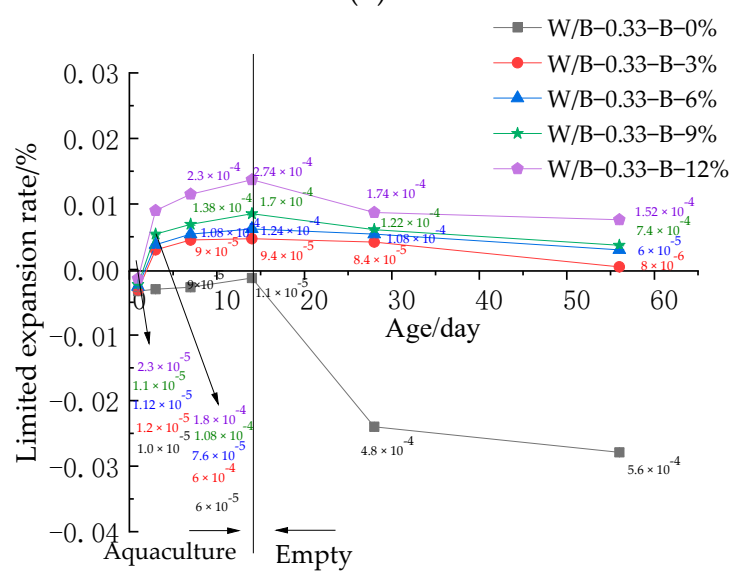

(d)

Figure 5. The limited expansion rate of concrete. (a) W/B-0.43 with 50\% mineral admixtures, (b) W/B- 0.43 with $60 \%$ mineral admixtures, (c) W/B-0.33 with 50\% mineral admixtures, (d) W/B-0.33with 60\% mineral admixtures. 


\subsection{The Research of Durability}

Figure 6 shows the carbonation depth of concrete varying with the content of expansive agents. As shown in Figure 6, the carbonation depth of concrete firstly decreases and then increases with the increasing dosage of expansive agents. Concrete with $6 \%$ expansive agents shows the lowest carbonation depth. This may be attributed to the fact that $\mathrm{CaO}$ in expansive agents is able to increase the amount of $\mathrm{Ca}(\mathrm{OH})_{2}$, therefore, a suitable dosage of expansive agents (lower than or equal to $6 \%$ ) results in improving the carbonation resistance of concrete and decreasing the carbonation depth [22,23]. However, a high dosage of expansive agents can make the concrete expand and reduce its compactness thus decreasing the carbonation resistance and increasing the carbonation depth $[24,25]$. Moreover, the increased dosage of mineral admixtures (fly ash and blast furnace slag) is able to increase the carbonation depth of concrete, due to the fact that the second hydration is improved by the addition of fly ash, thus consuming the amount of $\mathrm{Ca}(\mathrm{OH})_{2}$ and increasing the carbonation of concrete. Finally, it can be concluded by comparing Figure $6 \mathrm{a}, \mathrm{b}$, the decreasing water-binder ratio can decrease the carbonation depth due to the improved compactness of concrete by reducing the water-binder $[26,27]$.

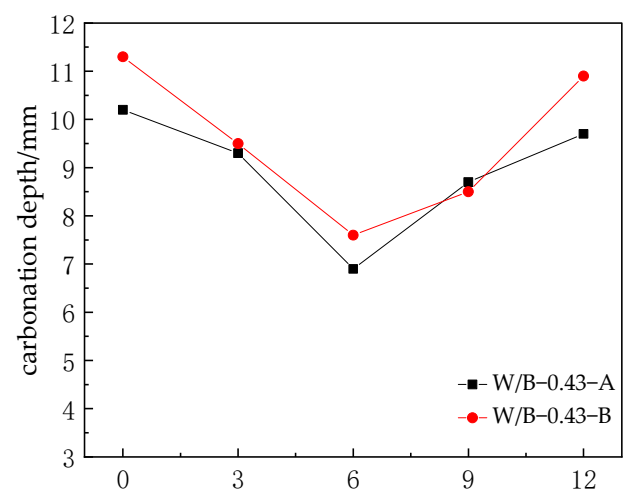

Dosage of dual expansion source expansion agent $/ \%$

(a)

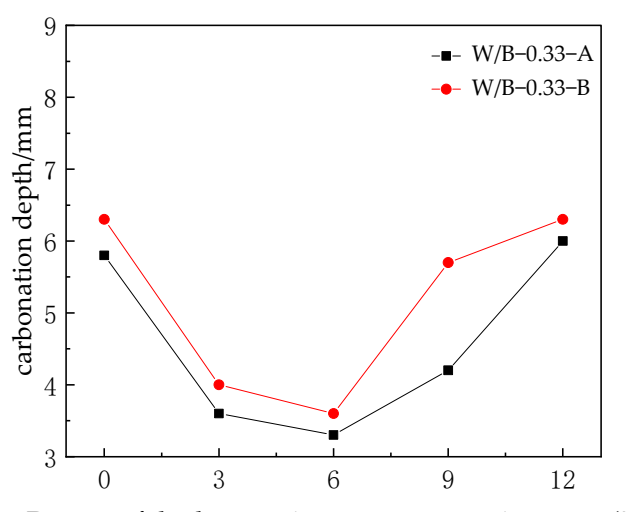

(b)

Figure 6. The carbonation depth of concrete. (a) W/B-0.43 with 50\% mineral admixtures, (b) W/B-0.33 with 50\% mineral admixtures.

Figure 7 shows the electric flux of concrete with different dosages of expansive agents. The electric flux is used to reflect the resistance to chloride ion penetration. As shown in Figure 7, the electric flux of concrete firstly decreases and then increases with the increasing dosage of expansive agents. When the dosage of expansive agents is $6 \%$, the electric flux is the lowest. Moreover, the decreased water-binder ratio can effectively decrease the electric flux of concrete. This is attributed to the fact that the compactness of cement concrete is improved by the decreased water-binder ratio thus improving the resistance to chloride penetration, consequently, the electric flux of concrete is decreased [28,29].

Figure 8 shows the weight loss rate of steel bars after exposure to a carbonation corrosion environment. As illustrated in Figure 6, the weight loss rate of steel bars firstly decreases and then increases with the increasing addition of expansive agents. This is attributed to the fact that suitable dosage of expansive agents (lower than or equal to 6\%) can improve the compactness of concrete, thus improving the corrosion resistance of steel bar-reinforced concrete and decreasing the weight loss rate $[30,31]$. However, excessive dosage (higher than 6\%) of expansive agents induces cracks in cement concrete, thus decreasing the corrosion resistance of steel bars in cement concrete and increasing the weight loss rate. 


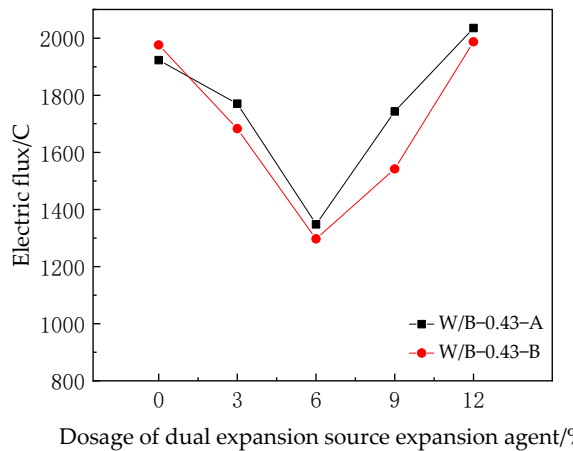

(a)

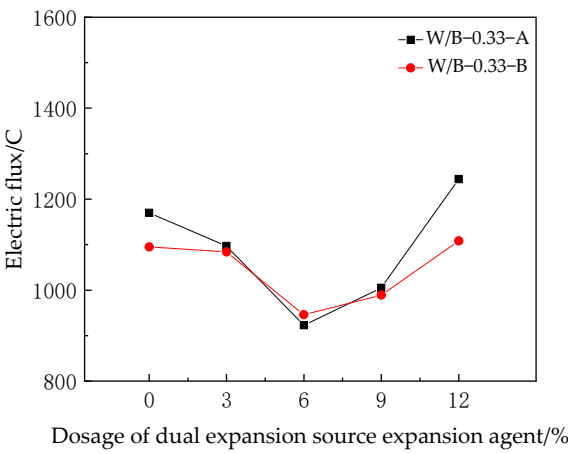

(b)

Figure 7. The resistance to chloride ion penetration. (a) W/B-0.43, (b) W/B-0.33.

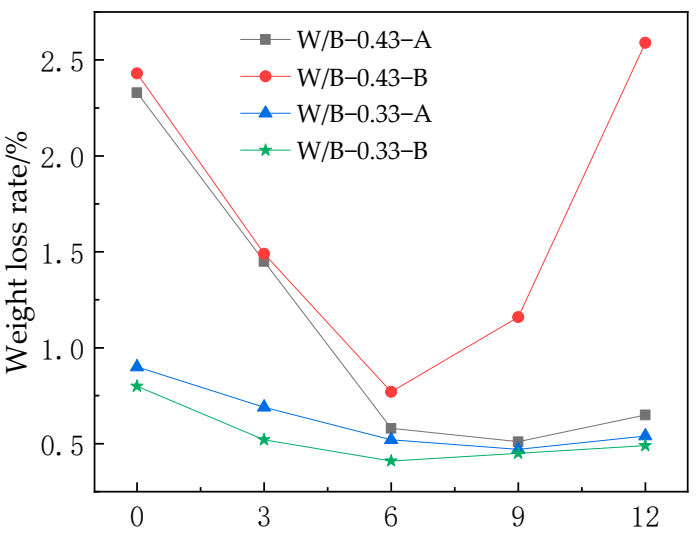

Dosage of dual expansion source expansion agent $/ \%$

Figure 8. The weight loss rate of steel bars in concrete.

\section{Conclusions}

In this research, the mechanical performance and durability of cement concrete with an assembly unit of expansive agents ( $\mathrm{CaO}$ and calcium sulphoaluminate) were investigated. The following corrosion resistance of reinforced cement concrete after exposing to carbonation corrosion environment was studied. The conclusions are as follows:

The limited and free compressive strengths firstly increased and then decreased with the increasing dosage of double expansion agent. The limited and free compressive strengths of cement concrete with $9 \%$ of double expansion agent reached the highest level.

The limited expansion of specimens with the addition of expansive agents rate firstly increased and then decreased with the increasing curing age. When the curing age was 14 days, the limited expansion rate was the highest. The limited expansion rate of concrete with 60\% mineral admixtures (fly ash and ground granulated blast furnace slag) was lower than the concrete with 50\% mineral admixtures. Moreover, concrete with $60 \%$ mineral admixtures showed better mechanical properties.

The incorporation of double expansion agent was able to result in the improvement of the resistance to carbonation, chloride ion penetration, steel corrosion and mechanical strength (the limited and free compressive strengths).

The decreased water-binder ratio led to improved compressive strength and resistance to carbonation, chloride ion penetration, steel corrosion, and decreased the expansion rate.

Author Contributions: Data curation, L.W., C.S., T.J., Y.H. and H.W.; Formal analysis, C.S. and Y.H.; Funding acquisition, H.W.; Investigation, L.W., T.J. and H.W.; Methodology, L.W.; Project administration, H.W.; Software, T.J.; Supervision, L.W.; Writing-original draft, L.W.; Writing-review and editing, H.W. All authors have read and agreed to the published version of the manuscript.

Funding: This work is sponsored by National Natural Science Foundation of China [No. 51878360]. 
Institutional Review Board Statement: Not applicable.

Informed Consent Statement: Not applicable.

Data Availability Statement: The data used to support the findings of this study are available from the corresponding author upon request.

Conflicts of Interest: The authors declare that there are no conflicts of interest regarding the publication of this paper.

\section{References}

1. Mo, Z.; Gao, X.; Su, A. Mechanical performances and microstructures of metakaolin contained UHPC matrix under steam curing conditions. Constr. Build. Mater. 2021, 268, 121112. [CrossRef]

2. Ren, G.; Yao, B.; Huang, H.; Gao, X. Influence of sisal fibers on the mechanical performance of ultra-high performance concretes. Constr. Build. Mater. 2021, 286, 122958. [CrossRef]

3. Yang, J.; Huang, J.; Su, Y.; He, X.; Tan, H.; Yang, W.; Strnadel, B. Eco-friendly treatment of ow-calcium coal fly ash for high pozzolanic reactivity: A step towards waste utilization in sustainable building material. J. Clean. Prod. 2019, 238,117962 [CrossRef]

4. Ruan, S.; Cise, U. Influence of supplementary cementitious materials on the performance and environmental impacts of reactive magnesia cement concrete. J. Clean. Prod. 2017, 159, 62-73. [CrossRef]

5. Guo, S.; Bu, Y.; Lu, Y. Addition of tartaric acid to prevent delayed setting of oilwell cement containing retarder at high temperatures. J. Petrol. Sci. Eng. 2019, 172, 269-279. [CrossRef]

6. Wang, H.; Zhang, A.; Zhang, L.; Liu, J.; Han, Y.; Shu, H.; Wang, J. Study on the influence of compound rust inhibitor on corrosion of steel bars in chloride concrete by electrical parameters. Constr. Build. Mater. 2020, 262, 120763. [CrossRef]

7. Wang, H.; Zhang, A.; Zhang, L.; Liu, J.; Han, Y.; Shu, H.; Wang, J. Research on the influence of carbonation on the content and state of chloride ions and the following corrosion resistance of steel bars in cement paste. Coatings 2020, 10, 1071. [CrossRef]

8. Ormellese, M.; Berra, M.; Bolzoni, F.; Pastore, T. Corrosion inhibitors for chlorides induced corrosion in reinforced concrete structures. Cem. Concr. Res. 2006, 36, 536-547. [CrossRef]

9. Leon, C.; Val, D. Prediction of corrosion-induced cover cracking in reinforced concrete structures. Constr. Build. Mater. 2011, $25,1854-1869$.

10. Mikulčić, H.; Cabezas, H.; Vujanović, M.; Duić, N. Environmental assessment of different cement manufacturing processes based on energy and ecological footprint analysis. J. Clean. Prod. 2016, 130, 213-221. [CrossRef]

11. Abdel-Gawwad, H.; Heikal, M.; Mohammed, M.; Abd El-Aleem, S.; Hassan, S.; Vasquez-Garcia, S.R.; Alomayri, T. Sustainable disposal of cement kiln dust in the production of cementitious materials. J. Clean. Prod. 2019, 232, 1218-1229. [CrossRef]

12. Jung, I.; Decterov, S.; Pelton, A. Critical thermodynamic evaluation and optimization of the CaO-MgO-SiO 2 system. J. Euro. Ceram. Soc. 2005, 25, 313-333. [CrossRef]

13. Soliman, A.; Nehdi, M. Effects of shrinkage reducing admixture and wollastonite microfiber on early-age behavior of ultra-high performance concrete. Cem. Concr. Compos. 2014, 46, 81-89. [CrossRef]

14. Park, S.; Ryu, G.; Koh, K.; Kim, D. Effect of shrinkage reducing agent on pullout resistance of high-strength steel fibers embedded in ultra-high-performance concrete. Cem. Concr. Compos. 2014, 49, 59-69. [CrossRef]

15. Ghafari, E.; Ghahari, S.; Costa, H.; Júlio, E.; Portugal, A.; Durães, L. Effect of supplementary cementitious materials on autogenous shrinkage of ultra-high performance concrete. Constr. Build. Mater. 2016, 127, 43-48. [CrossRef]

16. Liu, L.; Zhao, S.; Yang, B. Experimental study on the stability of RCC mixed with MgO. IOP Natl. Conf. Concr. Expans. Agents 2010, 39, 56-58.

17. Sherir, M.; Hossain, K.; Lachemi, M. Self-healing and expansion characteristics of cementitious composites with high volume fly ash and MgO-type expansive agent. Constr. Build. Mater. 2016, 127, 80-92. [CrossRef]

18. Temiz, H.; Kantarci, F.; Inceer, M. Influence of blast-furnace slag on behaviour of dolomite used as a raw material of MgO-type expansive agent. Constr. Build. Mater. 2015, 94, 528-535. [CrossRef]

19. Mo, L.; Deng, M.; Tang, M.; Al-Tabbaa, A. MgO expansive cement and concrete in China: Past, present and future. Cem. Concr. Res. 2014, 57, 1-12. [CrossRef]

20. Choi, S.; Jang, B.; Kim, J.; Lee, K. Durability characteristics of fly ash concrete containing lightly-burnt MgO. Constr. Build. Mater. 2014, 58, 77-84. [CrossRef]

21. El Haleem, S.A.; El Wanees, S.A.; El Aal, E.A.; Diab, A. Environmental factors affecting the corrosion behavior of reinforcing steel. IV. Variation in the pitting corrosion current in relation to the concentration of the aggressive and the inhibitive anions. Corros. Sci. 2010, 52, 1675-1683. [CrossRef]

22. Yoo, D.; Kang, S.; Lee, J.; Yoon, Y. Effect of shrinkage reducing admixture on tensile and flexural behaviors of UHPFRC considering fiber distribution characteristics. Cem. Concr. Res. 2013, 54, 180-190. [CrossRef]

23. Hargis, C.; Telesca, A.; Monteiro, P. Calcium sulfoaluminate (Ye'elimite) hydration in the presence of gypsum, calcite, and vaterite. Cem. Concr. Res. 2014, 65, 15-20. [CrossRef] 
24. Glasser, F.; Zhang, L. High-performance cement matrices based on calcium sulfoaluminate-belite compositions. Cem. Concr. Res. 2001, 31, 1881-1886. [CrossRef]

25. van Zijl, G.; Slowik, V.; Toledo Filho, R.D.; Wittmann, F.; Mihashi, H. Comparative testing of crack formation in strain-hardening cement-based composites (SHCC). Mater. Struct. 2016, 49, 1175-1189. [CrossRef]

26. Qin, L.; Gao, X.; Su, A.; Li, Q. Effect of carbonation curing on sulfate resistance of cement-coal gangue paste. J. Clean. Prod. 2020, 278, 123897. [CrossRef]

27. Li, J.; Yang, S.; Liu, Y.; Muhammad, Y.; Su, Z.; Yang, J. Studies on the properties of modified heavy calcium carbonate and SBS composite modified asphalt. Constr. Build. Mater. 2019, 218, 413-423. [CrossRef]

28. James, A.; Bazarchi, E.; Chiniforush, A.; Aghdam, P.P.; Hosseini, M.R.; Akbarnezhad, A.; Martek, I.; Ghodoosi, F. Rebar corrosion detection, protection, and rehabilitation of reinforced concrete structures in coastal environments: A review. Constr. Build. Mater. 2019, 224, 1026-1039. [CrossRef]

29. Lei, L.; Wang, Q.; Xu, S.; Wang, N.; Zheng, X. Fabrication of superhydrophobic concrete used in marine environment with anti-corrosion and stable mechanical properties. Constr. Build. Mater. 2020, 251, 118946. [CrossRef]

30. Aïtcin, P. Demystifying autogenous shrinkage. Concr. Int. 1999, 21, 54-56.

31. Xu, L.; Deng, M. Dolomite used as raw material to produce MgO-based expansive agent. Cem. Concr. Res. 2005, 35, 1480-1485. 